\title{
EFL Epistemic Beliefs, Writing Apprehension, Writing Strategies, Writing Performance: Exploring Possible Relationships
}

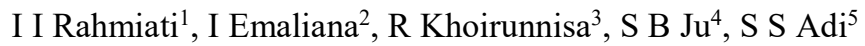 \\ $1,2,5$ Universitas Brawijaya, Malang, Indonesia \\ ${ }^{3}$ Putera Sampoerna Foundation, Jakarta, Indonesia \\ ${ }^{4}$ Busan University of Foreign Studies, South Korea \\ \{1ismarita_ida@ub.ac.id 2ive@ub.ac.id 3rizqi.khoirunnisa@sampoernaschoolssystem.com \\ ${ }^{4}$ sbj6772@naver.com ${ }^{5}$ sugengadi@ub.ac.id\}
}

\begin{abstract}
This study, aimed at investigating the relationship among EFL university students' epistemic beliefs, apprehension, learning strategies, and writing achievement, was conducted in one of Indonesian state universities. There were 99 EFL undergraduate students who were taking essay writing class participating in the study. The students' responses to EFL epistemic beliefs, writing apprehension, and writing strategies questionnaires are explored via partial least square. It was concluded that the contribution of epistemic beliefs and writing strategies showed positive correlations with writing achievement and writing apprehension had negatively low correlation with writing achievement. Further, practical and theoretical implications were depicted for EFL writing learning and teaching, followed by statements of limitation.
\end{abstract}

Keywords: EFL, Writing strategies, EFL Epistemic beliefs, Achievement, Writing Anxiety

\section{INTRODUCTION}

An English as a foreign language (EFL) educators have long been concerned about the impact of individual difference aspects including motivation, aptitude, anxiety, learning strategies, and beliefs on English language learning, notably in writing performance. One of numerous benefits ascribed to consider those individual differences is that it serves an essential process and ultimate goal of language learning in writing classrooms. Substantial attention has been emphasized that enhancing students' writing performance, as it is one of ultimate goals of learning English. As one of productive skills, teaching writing should be also seen from students' individual difference factors which influence learning, so that a proming teaching technique, methods, media, and materials accommodate the learning atmosphere.

Considerable studies have been devoted to revealing how those individual differences impact among others. In their study, [1] mention that beliefs about writing projected aspects in writing scores excess writing self-efficacy and apprehension. In relation to writing selfefficacy beliefs which shows moderate correlation with writing scores, some results are reveals, i.e (1) audience orientation, is the most robust positive predictor for students' achievement; (2) transmission (a belief in depending on authorities' learning materials) shows negative correlation. Another variable in relation to apprehension is disseminated 
unexpectedly, like apprehension about becoming critique is not significant and anxiety about grammar is negatively correlated. Therefore, these findings add the chance that beliefs about writing can be power point for the teaching of writing.

More recent studies has extended students' individual differences which affect writing performance. Different from writing self-efficacy beliefs (namely students' beliefs about their own writing skill, they mention what good writing is and what good authors do), EFL epistemic beliefs review the whole beliefs of students' view on students' identification on learning English, and some of their ways to learn English. The EFL epistemic beliefs portray bigger constructs and concepts inside the students' reasons in learning EFL. It emphasizes the prominent role of teaching and learning approach as the foundation of philosophical beliefs which is applied in the teaching and learning methods and techniques which has been received and internalized by the students[2]. This leaves the gap for the present study to do compare to self-efficacy beliefs and beliefs in writing.

Besides, writing apprehension appears to be another factor affects learning. [3] mention that contradictory results obtained in former research guided researchers to examine sufficiency of transfer approach and move to a situation-specific approach which forms a concept about EFL apprehension as a unique category caused in the process of learning or utilizing English. Negative associations between foreign language anxiety and achievement are usually shown [4], yet positive correlation is also shown as in [1]'s study. Besides that, students rely on various kinds of writing strategies while writing in foreign language, as they may assemble ways or ideas to structure their texts prior to writing, constantly read their own texts during writing to make them flow logically [5]. These series of writing strategies appear to give impact to students' writing performance.

Induced by previous ideas about aspects affecting writing, current research presents an evaluative viewpoint about correlations among them. Similar to [1]'s study that learners' beliefs about writing correlate to writing performance, self efficacy, and apprehension, the present study focuses on the EFL epistemic beliefs which relate to writing apprehension and writing strategies to predict students' performance.

As former research have projected some distinctive ways for developing and gaining writing achievement in learning, among them is a remark to beliefs about knowledge and knowing, namely epistemic beliefs, are connected to achievement and cognition. Students' writing performance tends to be higher when teachers aid students in developing and enhancing their beliefs through adjusting to their sophisticated beliefs from simple primary ones [6]. Students have more interest, internal self efficacy, goal orientation, and self regulated learning to reach high degree of academic achievement when they posses sophisticated epistemic beliefs [7].

Therefore, the prediction of the existence of causal relationship chain happen among the EFL epistemic beliefs, writing apprehension, writing strategies and writing performance use can be obtained in EFL writing context, albeit mainly former studies do not explore directly and precisely direction of correlation amongst them commencing from epistemic beliefs. Nevertheless, there is a growing body of published studies establishing feasible linkages between them, especially, epistemological beliefs affects writing apprehension, which impact achievement indirectly [8] and learning strategies [9]. Generally, it is considered that epistemic beliefs is the most influential factor to affect writing apprehension and so writing strategies use, which becomes the gap to be filled in this present study.

On the basis of empirical and theoretical backdrops, the hypothesized model depicted in Figure 1 and tested the fit of the model to data. Considering the current manifestations and a great number theories taken from results in research about the study of probable correlations 
between the EFL epistemic beliefs, writing apprehension, writing strategies use and writing performance; thus, theoretical model hypothesis about the causal relationship among them is established.

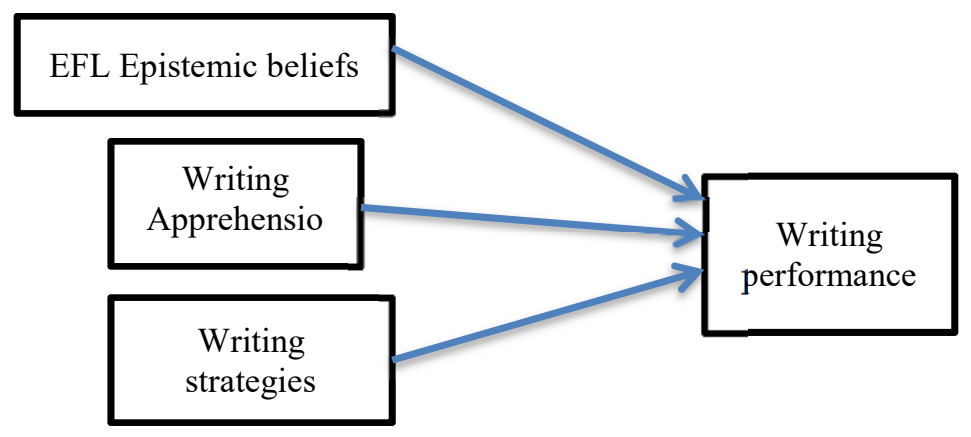

Figure 1. Tested Model

Consequently, findings of the current study enumerate procedures which students employ when the posses a certain degree of epistemic beliefs to correlate their writing apprehension that will influence their options to utilize notable writing strategies to understand writing materials and to develop compositions. In breadth, the current study findings have connections for the teaching of writing.

For the abovementioned reasons, the present study addresses the following research questions. "Is there any relationship among EFL epistemic beliefs, writing apprehension, writing strategies and writing performance?"

In finding the answer for the research problem, the hypotheses are composed. The first hypothesis is that the EFL epistemic beliefs are correlated with writing apprehension. The second hypothesis is that writing apprehension has relation with writing strategies. The third hypothesis is that writing strategies are correlated with writing performance. Therefore, an assumption is about the mediating role of writing apprehension and writing strategies EFL between epistemic beliefs and writing performance. It means that EFL epistemic beliefs have causal relationship writing performance indirectly through direct effect on writing apprehension and writing strategies. Accordingly, the design employed in the present study follows structural equations correlation.

\section{RESEARCH METHOD}

The objective of the study is aiming at knowing the causal relationship among EFL epistemic beliefs, writing apprehension, and writing strategies. The results of this study might be significant to the input of appropriate teaching materials, media, techniques and approach. This would be beneficial to the lecturers as it can be a good input to the teaching of Essay Writing class.

\subsection{Participants}

The participants of this research were 128 students who volunteered from five Essay Writing classes in academic year 2017/2018. Essay Writing was presented in semester 3 (three). The objective of this course is students are able to compose essays written in English. However, among all participants, only 99 students were eligible to be proceeded as the data. 


\subsection{Instrument}

There were two types of instruments; they are questionnaires and writing performance. The questionnaires consisted of three parts, i.e. students' EFL epistemic beliefs [2], writing strategies [5], and writing apprehension [3]. The EFL epistemic beliefs consisted of 39 items, which items were valid and reliable, for only items which manifested obtained coefficient less than .05 were confirmed valid. Cronbach's alpha $(\alpha)$ was used to measure internal consistency reliability coefficients of adopted epistemic beliefs for seven dimensions as follows: certain knowledge $(\alpha=.519)$, fix ability $(\alpha=.702)$, foreign language aptitude $(\alpha=.515)$, learning and communication strategies $(\alpha=.463)$, motivation and expectation $(\alpha=.624)$, omniscient authority $(\alpha=.480)$, simple knowledge $(\alpha=.582)$. Thus, the questionnaire, notably in EFL epistemic beliefs part is reliable.

Students' writing strategies: in order to know students' writing strategies the English writing strategy inventory from [5] was utilized (24 items). The items which obtained coefficients less than .05 were valid, unless they were not used for maintaining the questionnaire validity. Accordingly, measuring internal consistency reliability coefficients of the questionnaire, Cronbach's alpha coefficient $(\alpha)$ were employed for the four dimensions, namely before writing $(\alpha=.707)$, whilst writing $(\alpha=.710)$, after writing $(\alpha=.707)$, to improve $(\alpha=.799)$. These statistical results were evidence of the reliability of the questionnaire in students' writing strategies part.

Students' writing apprehension: in order to measure students' anxiety in writing, the questionnaire (9 items) was used. Similarly, validity and reliability of the questionnaire were measured through SPSS 20, and each item demonstrated less than .05 coefficient was claimed valid. The internal consistency reliability of this questionnaire was showed by Cronbach's alpha $(\alpha)$ as follows: behavioral $(\alpha=.748)$, cognitive $(\alpha=.866)$, and somatic $(\alpha=.876)$. It means the questionnaire, for students' writing apprehension variable is reliable.

The second instrument was students' writing performance which was taken from students' final scores, which consisted of active participation (10\%), quizzes (15\%), assignments (20\%), mid-term test (25\%), and final test (30\%) scores.

\subsection{Procedures}

There were several procedures undergone in this study. First, 128 students filled in each questionnaire, however only 99 among them were used as the data due to consideration of completeness of responses of the questionnaires. The questionnaires fillings were administered in four different classes ten minutes before or after the class session, based on the lecturers' convenience. The questionnaires were distributed in three different meetings in each class. Upon providing consent to participate in the questionnaires students were directed to respond to each item of the questionnaire. Completing the questionnaire was not part of the class requirements and no additional credit was given to students who completed them. The second instrument which was the students' final scores in Essay Writing class was taken after the score was submitted to the academic office. The scores could be accessed after they were legally published by the academics. They were taken from the administration staff with the permission letter. 


\subsection{Data Analyses}

Partial Least Square (PLS) was run to find out the contribution of each dimension in EFL epistemic beliefs, writing strategies, and writing anxiety to writing achievement. SmartPLS 3 software was utilized in conducting the analysis. PLS was proposed for predictive analysismaximizing the variance explanation for all constructs- where prior theoretical knowledge was scare and the problems were complex [10]. The theoretical basis of research on EFL epistemic beliefs was growing progressively because the previous finding was not yet completely conclusive, for only one study was conducted by using epistemic beliefs in EFL setting, but it did not even use the specific EFL epistemic beliefs [11].

PLS did not need independent observations nor apply distributional assumptions for measured variables, so it allowed the use of interval, ordinal, or nominal-scaled variables [10]. In the present research each dimension of EFL epistemic beliefs belonged to ordinal-scaled variable and writing scores belonged to interval-scaled variable. Regarding the strength of the relationship, the range of a figure between 0.99-0.60 reflects a considerable high relationship, while a figure between 0.59-0.30 represents a moderate relationship, and 0.29-0.01 represents a low relationship. [12] determines that knowing the obtained significant value is also important to know whether the value is significant (below 0.05) or not significant (exceed $0.05)$.

\section{RESULTS AND DISCUSSION}

As this present research, a better picture of how EFL epistemic beliefs, writing strategies, and writing anxiety correlate with writing achievement by using more powerful and thorough correlation analysis through PLS analysis. Figure 2 showed the results of correlation among them and also correlation among latent variables which constructed each variable.

Figure 2.

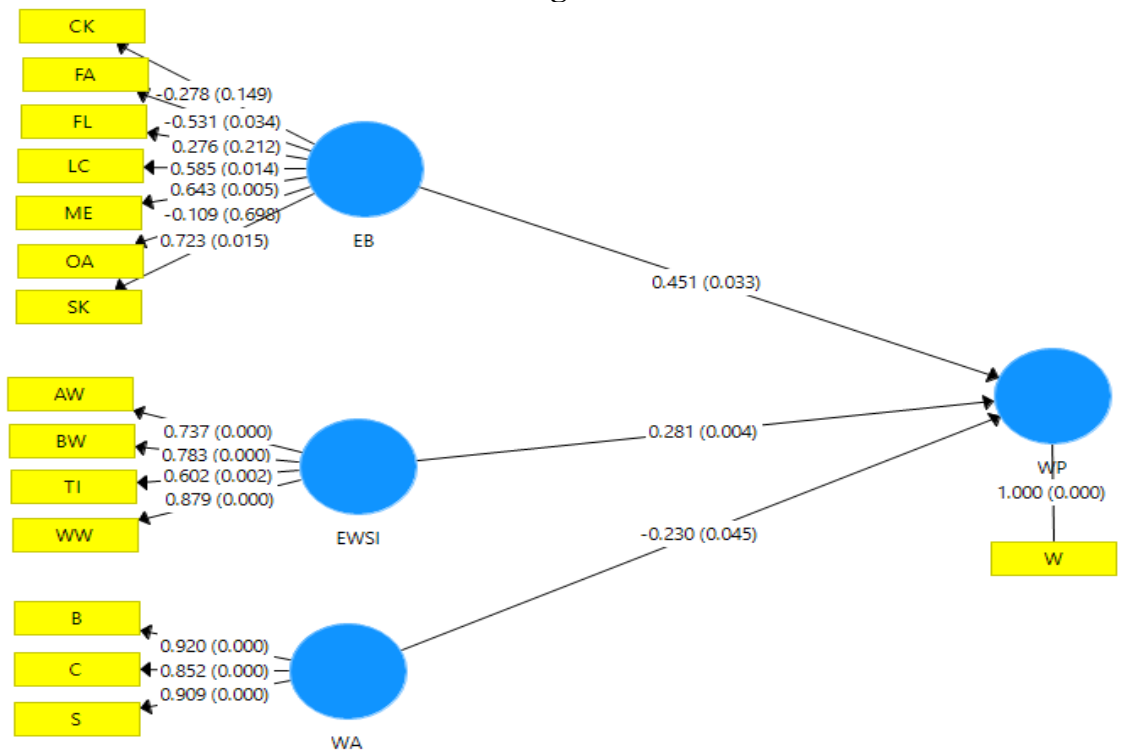

From Figure 2, it revealed that correlation between EFL epistemic beliefs (EB) and writing performance (WP) was .451 ( $p$-value $=.033)$; correlation between English writing strategy 
inventory (EWSI) and WP was 281 ( $p$-value $=.004)$; and correlation between writing anxiety and WP was -.230 ( $p$-value $=.045)$. All of the correlations were significant because the $\mathrm{p}$ values of all skills were lower than significance level .05 . These meant that EB and EWSI had positive correlation with WP; but EB had moderate correlation, while EWSI had low correlation. However, WA had negative and low correlation with WP.

According to the results of the correlation, certain knowledge, foreign language aptitude, and omniscient authority were not significant to epistemic beliefs. It meant that discussions about epistemic beliefs was focused on variable how to acquire English as knowledge, notably fix ability, learning and communication strategies, motivation and expectation, and simple knowledge. According to the results, fix ability had significant correlation with epistemic beliefs, but it showed negatively moderate relationship. The students who had good writing performance tended to have learning paradigm that ability to learning English especially writing skill is inherited.

Based on the results, students who show good performance in writing do not specifically define what is learning English through only one teaching and learning approach. Every student with various beliefs on learning English writing will have the same opportunity to get good score in writing. Students can have beliefs that learning English with grammar translation method, cognitive, second language acquisition, or communicative approach, have equal chance to be high achievers.

In relation to the second dimension of epistemic beliefs, i.e. how to learn English. Firstly, in relation to fixed ability, students' epistemic beliefs are influenced more with concept of learning English can improve over time. Secondly, regarding learning and communication strategies, students epistemic beliefs are influenced more with concept of actual language learning practices and communication strategies. Thirdly, related to motivation and expectation, students' epistemic beliefs are influenced more with desires and opportunities to associate with the learning of English language. Fourthly, simple knowledge deals with students' epistemic beliefs which are more influenced with concept of learning English is acquired through reasons or logics, so it is tentative, flexible, and constantly changing.

According to the results of the correlation, all dimensions of English writing strategy inventory were significant and showed positively high relationships. According to the results, the students who had good writing performance tended to considerably utilize their before, while, after writing strategies and kept on trying to improve their writing with several ways. In other words, students' English writing strategies are influenced with their before writing, when writing, after writing, and some others strategies to improve their writing. Some concepts of Before Writing strategies which are meaningful are considering assessment rubrics, requirement of writing tasks, make writing purpose be clear, generating ideas which cross in minds with first language: bahasa Indonesia and refer to a variety of reading materials, and making outlines, usually in bahasa Indonesia. Some concepts of When Writing strategies include rechecking logical flows, rereading writing purposes, seeking additional materials by reading, and using bahasa Indonesia before translating into English whenever having troubles writing. Some concepts related to After Writing strategies are rereading final draft thoroughly, assessing writing for its topic and supporting ideas effectiveness, utilizing dictionary to consult spellings, and reviewing the works and correcting typos and grammatical errors.

According to the results of the correlation, all dimensions of writing anxiety were significant and showed positively high relationships. According to the results, the students who had good writing performance tended to be less anxious for cognitive, somatic and behavioral anxiety. Some concepts of behavioral anxiety include giving up easily when practicing writing compositions, skimping over composition exercises, and avoiding writing 
composition. Some concepts related to cognitive anxiety include worrying to make language mistakes, worrying the writing performance is worse than others, and worrying not being able to express themselves.

Several pedagogical implications can be revealed from this findings and discussion. Firstly, the results of the study can be the basis of developing course profile in the English language department study program curriculum, especially in modifying focus for writing course. This should accommodate equal ELT approaches in the teaching of writing, i.e. grammar translation, cognitive, second language acquisition, and communicative approaches. This finding is supported by [13], that teachers should advance rigorous understanding of the beliefs under the basis of students' engagement with EFL writing activities and tasks in more various ways. Besides, it is possible to promote conducive beliefs development to deep engagement with students' epistemic beliefs, by exposing students to diverse teaching and learning approaches, offering students ample chances to engage in writing assignments.

Secondly, more specific to teaching techniques, students are predicted to have good achievement in writing if they are exposed to teaching and learning activities that provide concepts that learning is flexible. Thus, students need to be exposed more practices are needed to boost the writing achievement, especially through before, while, and after teaching writing [14]. In addition to this, [15] explains that through process writing, students who previously struggled to write, now have a growing awareness to involve in learning process because pre, while, and post writing activities can effectively support their writing with inefficient English language proficiency because they are guided to writing practices in the class.

Thirdly, more friendly and less stressing writing activities are predicted to add students' achievement in writing. As mentioned by [16], the basic reasons of students' writing anxiety mostly stem from schemata, linguistic competence and affective factors insufficiency, and these lacks can be decreased through process writing which includes pre, while, and post writing activities.

\section{CONCLUSIONS}

The current research presents implication for EFL writing instruction. Generally, EFL writing lecturers can employ the findings to better understanding on some characteristics which influence their students' achievement. This study indicated that epistemic beliefs, writing strategies, and writing anxiety were significant predictors that can highlight individual differences in writing performance. Therefore, lecturers should consider the possibilities, supervise students' writing performance, and if necessary, modify the manner of presenting learning tasks or teaching materials so that students have better achievement in writing.

Several limitations of the research are recognized. The samples were a specific group of Indonesian EFL learners from one state university, limiting the generalizability of findings to a wider population of EFL students. Nonetheless, a fairly homogeneous group of EFL students in their linguistic, cultural, and educational background, and in the setting of EFL learning become strengths of this study. Therefore, further research should present a rationale for these or other choices as much has been discussed on this issue, like researching continued inquiry particularly on the relationship among students' characteristics longitudinal study.

\section{REFERENCES}

[1] J. Sanders-Reio, P. A. Alexander, T. G. Reio, and I. Newman, "Do students' beliefs about writing relate to their writing self-efficacy, apprehension, and performance?," Learn. Instr., vol. 33, pp. 1-11, Oct. 2014. 
[2] I. Emaliana and N. Lailiyah, "SOPHISTICATED EPISTEMIC BELIEFS: AN INTERPRETATIVE PHENOMOLOGICAL ANALYSIS OF STUDENTS' TASKBASED LEARNING EXPERIENCES," Erud. J. Educ. Innov., vol. 5, no. 1, pp. 124-135, Jul. 2018.

[3] Y. Cheng, "Development and preliminary validation of four brief measures of L2 language-skill-specific anxiety," System, vol. 68, pp. 15-25, Aug. 2017.

[4] E. Horwitz, "Language anxiety and achievement," Annu. Rev. Appl. Linguist., vol. 21, Jan. 2001.

[5] M. Hwang and H.-K. Lee, "Development and validation of the English writing strategy inventory," System, vol. 68, pp. 60-71, Aug. 2017.

[6] E. M. Sosu and D. S. Gray, "Investigating change in epistemic beliefs: An evaluation of the impact of student teachers' beliefs on instructional preference and teaching competence," Int. J. Educ. Res., vol. 53, pp. 80-92, Jan. 2012.

[7] U. Ulucinar, C. Akar, M. Demir, and G. Demirhan, "An Investigation on Epistemological Beliefs of University Students," Procedia - Soc. Behav. Sci., vol. 46, pp. 5133-5137, 2012.

[8] B. Kizilgunes, C. Tekkaya, and S. Sungur, "Modeling the Relations Among Students' Epistemological Beliefs, Motivation, Learning Approach, and Achievement," J. Educ. Res., vol. 102, no. 4, pp. 243-256, May 2009.

[9] N. Mellat and M. G. Lavasani, "The Role of Epistemological Beliefs, Motivational Constructs and Information Processing Strategies in Regulation of Learning," Procedia Soc. Behav. Sci., vol. 30, pp. 1761-1769, 2011.

[10] V. Esposito Vinzi, Ed., Handbook of partial least squares: concepts, methods and applications. Berlin; New York: Springer, 2010.

[11] Akbari, R. and Karimi, M.N, "EFL Students' Proficiency Outcomes: What do Epistemological Beliefs Have to Offer?," Asian EFL J. Q., vol. 15, no. 3.

[12] Butler, C.S., Statistics in Linguistics. Oxford: Basil Blackwell.

[13] Y. Han, "Mediating and being mediated: Learner beliefs and learner engagement with written corrective feedback," System, vol. 69, pp. 133-142, Oct. 2017.

[14] J. Wang, K. Spencer, and M. Xing, "Metacognitive beliefs and strategies in learning Chinese as a foreign language," System, vol. 37, no. 1, pp. 46-56, Mar. 2009.

[15] A. K. A. Faraj, "Scaffolding EFL Students' Writing through the Writing Process Approach," J. Educ. Pract., p. 12, 2015.

[16] Pimsarn, P, “EFL Students' Writing Apprehension,” Int. J. Arts Sci., vol. 6, no. 4, pp. 99109. 